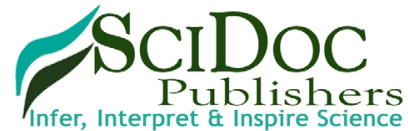

International Journal of Diabetology \& Vascular Disease Research (IJDVR) ISSN:2328-353X

\title{
TRACK Implementation among Bangladeshi Population
}

Research Article

Mohiuddin $\mathrm{AK}^{*}$

Secretary and Treasurer, Dr. M. Nasirullah Memorial Trust, Tejgaon, Dhaka, Bangladesh.

Abstract

With the increasing burden of non-communicable diseases in low-income and middle-income countries (LMICs), biological risk factors, such as hyperglycemia, are a major public health concern in Bangladesh. Optimization of diabetes management by positive lifestyle changes is urgently required for prevention of comorbidities and complications, which in turn will reduce the cost.Diabetes had 2 times more days of inpatient treatment, 1.3 times more outpatient visits, and nearly 10 times more medications than non-diabetes patients, as reported by British Medical Journal. And surprisingly, $80 \%$ of people with this so called "Rich Man's Disease" live in low- and middle-income countries. According to a recent study of American Medical Association, China and India collectively are home of nearly 110 million diabetic patients. The prevalence of diabetes in this region is projected to increase by $71 \%$ by 2035 . Bangladesh was ranked as the $8^{\text {th }}$ highest diabetic populous country in the time period of 2010-2011. In Bangladesh, the estimated prevalence of diabetes among adults was $9.7 \%$ in 2011 and the number is projected to be 13.7 million by 2045. The cost of diabetes care is considerably high in Bangladesh, and it is primarily driven by the medicine and hospitalization costs. According to Bangladesh Bureau of Statistics, in 2017 the annual average cost per T2DM was $\$ 864.7$, which is $52 \%$ of per capita GDP of Bangladesh and 9.8 times higher than the general health care cost. Medicine is the highest source of direct cost (around 85\%) for patients without hospitalization. The private and public financing of diabetes treatment will be severely constrained in near future, representing a health threat for the Bangladeshi population.

Keywords: Blood Sugar Screening; Compliance; Overweight; Lifestyle; Regular Health Checkup; Ramadan Fasting; Climate Issue of Diabetes.

Abbreviations: Low- And Middle-Income Countries(LMICs); International Diabetes Federation (IDF); National Eye Health Education Program (NEHEP); Bangladesh Demographic and Health Survey (BDHS); Bangladesh Institute of Research and Rehabilitation in Diabetes, Endocrine and Metabolic Disorders (BIRDEM); Institute of Public Health (IPH).

\section{Background}

Bangladesh is among the top 10 countries with the highest rates of projected age-standardized mortality among selected LMICs due to chronic diseases, particularly for CVDs and diabetes [1]. The age adjusted death rate 40 per 100,000 of population ranks Bangladesh 57 in the world, says WHO [2]. Diabetes is one of the four major types of non-communicable diseases that make the largest contribution to morbidity and mortality worldwide. The International Diabetes Federation (IDF) estimated that, worldwide, approximately 425 million people had diabetes in 2017 , projected to be 629 million by 2045 . Again, worldwide $\$ 727$ billion was spent in 2017 for treating and preventing diabetes, projected to be US\$776 billion by 2045 [2]. In Bangladesh, specifically, the IDF projects the prevalence of diabetes will increase to more than $50 \%$ in the next 15 years [4]. About 129,000 deaths were attributed to diabetes in Bangladesh in 2015, as reported by leading research organization ICDDR, B [5]. According to the WHO-Diabetes country profile of Bangladesh in 2016, the physical inactivity was prevailing among $25.1 \%$ of population [6]. Around $85 \%$ population of age group 25-65 never checks for diabetes [7]. A recent study by British Medical Journal says, 1 in 10 Bangladeshi adults aged $\geq 18$ years have hyperglycemia (among urban residents) [4]. Even in rural Bangladeshi community, undiagnosed diabetes was high, 7.2\% found in a $2016[8]$ and $10 \%$ in 2019. Roughly $20 \%-30 \%$ of adults in rural areas of Bangladesh have abnormal fasting glucose or impaired glucose tolerance, with the prevalence of diabetes (mostly type 2 diabetes) expected to

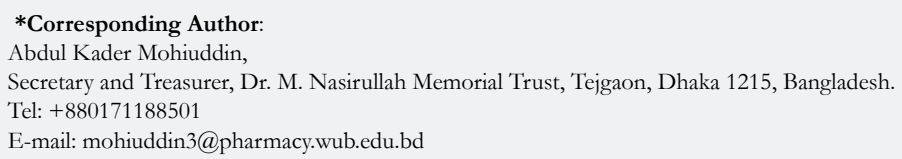

Citation: Mohiuddin AK. TRACK Implementation among Bangladeshi Population. Int J Diabetol Vasc Dis Res. 2019; 7(4):254-260. doi: http://dx.doi.org/10.19070/2328-353X-1900048

Copyright: Mohiuddin $\mathbf{A K}^{\circ}$ 2019. This is an open-access article distributed under the terms of the Creative Commons Attribution License, which permits unrestricted use, distribution and reproduction in any medium, provided the original author and source are credited. 
Figure 1. TRACK, a program of National Institute of Health (NIH), England to memorize the factors that can contribute to health while living with diabetes [14].
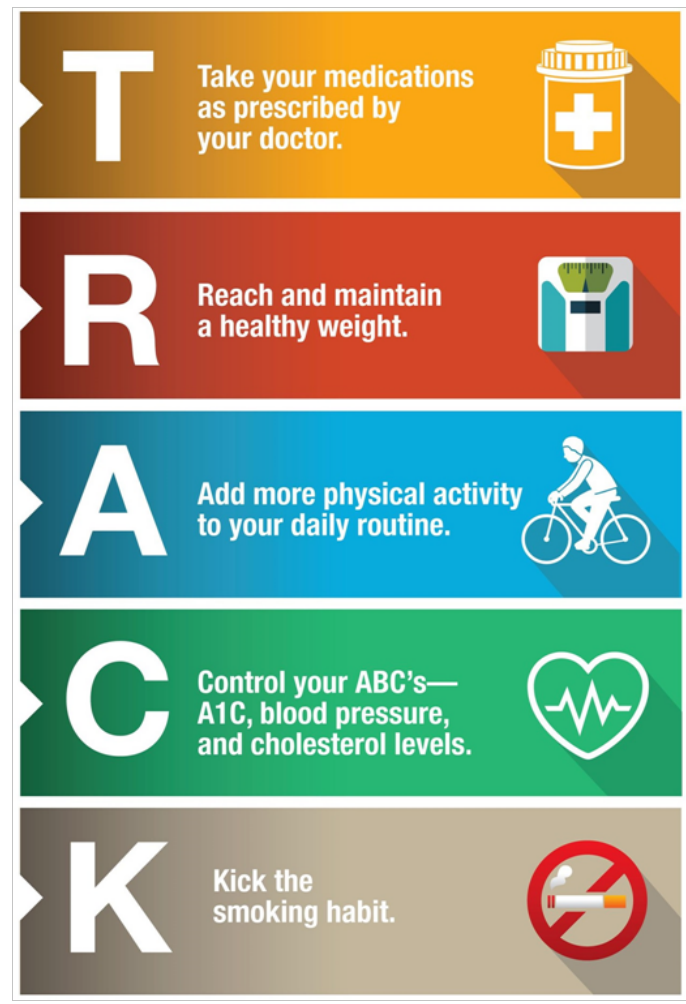

reach $24 \%-34 \%$ by 2030 [9]. And IDF says, there are 7.1 million people with undetected diabetes in Bangladesh and this number will be double by 2025 [10]. Das et.al, 2019 reported prevalence of dyslipidemia was over $70 \%$ to both male and female subjects, which indicates the urgency of lifestyle intervention strategies to prevent and manage this important health problem and risk factor [11]. Among 8400 stroke patients from different hospitals in Bangladesh over a period of sixteen years, diabetic patients were nearly $25 \%$ [12]. Prevention strategies should focus on increasing physical activity, weight loss, smoking cessation, and stricter control of hypertension and glycemic level [13].

\section{Material and Methods}

\section{The TRACK Concept}

National Eye Health Education Program (NEHEP) developed a tool using the word "TRACK" to help you remember how to stay on track with diabetes. To keep blood sugar level on target and avoid problems with eyes, kidneys, heart and feet, patients should eat right and be active, and may need to take medication. This helps them make choices in eating and being active so body can perform at its best. By regularly monitoring, patients get it on track and prevent long-term health problems [14, 15]. TRACK was developed for diabetic retinopathy prevention but in real life it prevents all other diabetic complication by disease progression. The criteria, in short are regular health checkup and compliance of treatment guidelines along with some lifestyle modifications.

\section{Methodology}

Research conducted a year-round comprehensive literature search, which included technical newsletters, newspapers journals, and many other sources. The present study was started at the beginning of 2019. PubMed, ALTAVISTA, Embase, Scopus, Web of Science, and the Cochrane Central Register were thoroughly searched. The keywords were used to search for different publishers' journals such as Elsevier, Springer, Willey Online Library, and Wolters Kluwer which were extensively followed. Medicine and technical experts, pharmaceutical company representatives, hospital nurses, and journalists were given their valuable suggestions. Projections were based on TRACK criteria of regular health checkup by diabetic and non-diabetic Bangladeshi population. There are many studies regarding diabetes in Bangladeshi population. This is the first study so far, where TRACK criteria (suggested by NEHEP of National Institute of Health, England) fulfillment is studied in Bangladesh.

\section{Results and Discussion}

\section{TRACK Vs Bangladesh: Perplexity of the Present Situation}

\section{Compliance Issue}

Poor adherence is a well-documented obstacle in therapeutic control of diabetes. For an effective control and prevention of diabetes, $87 \%$ of Bangladeshis were noncompliant, compared to $71 \%$ of Indians and $52 \%$ Europeans [16]. Out-of-pocket expenditure, emotional status, frequency of counseling, patient's family priorities, availability of medication (mainly insulin) are the factors greatly influence patient compliance to treatment guidelines. In 2016, the median monthly cost of diabetes maintenance was close to $\$ 10$, approximately $10 \%$ of the median monthly income [17]. According to a $2018 \mathrm{BBC}$ record, insulin availability found supplies were low in six countries - Bangladesh, Brazil, Malawi, Nepal, Pakistan and Sri Lanka [18]. Also, huge gap between the number of diabetic patients and doctors are well-known. The Diabetic Association of Bangladesh (DAB) 
record shows, except Dhaka and Chittagong, there are no tertiary facilities in Bangladesh to preventing blindness due to diabetic retinopathy [19]. Children with diabetes are still managed by adult physicians or occasionally by adult diabetologists, except in institutions like BIRDEM, and Dhaka Shishu Hospital. Children and adolescents have special needs at different stages e.g., nutrition, schooling, growth, puberty etc. Improving detection, awareness, and treatment strategies is urgently needed to prevent the growing burden associated with diabetes [20].

\section{Overweight Issue}

Overweight or obese children have a higher risk of becoming obese in adulthood and are at higher risk of associated chronic diseases [21]. Al Muktadir et.al, 2019 revealed that around 22\%to $27 \%$ Bangladeshi youth were recorded as obese with different stages of obesity [22]. Another study says nearly $40 \%$ Bangladeshi youth, taking fast foods were recognizedas overweight where $32 \%$ were noted as obese with different phases of obesity and overall prevalence of fast food consumption was about $53.8 \%$ [23]. In a newspaper interview, Professor AK Azad Khan, President, Diabetic Association of Bangladesh said 40\% school going children of Dhaka city were either obese or overweight [24]. "Children with type 2 diabetes is rising "alarmingly" in Bangladesh. A 300\% raise in the last five years", according to the Changing Diabetes in Children Program of the BIRDEM hospital [25]. A community level study shows $35 \%$ of mothers perceived that childhood overweight/obesity could be a health problem and nearly $70 \%$ were not aware of any health consequences of childhood obesity [26]. Another study shows 97.4\% students consume fast food contain Monosodium Glutamate which causes obesity and other body discomforts [27]. In a similar study among students of 4 private universities of Dhaka, $98 \%$ of the students were well informed about the negative effects associated with excessive fast food consumption, they were still profoundly addicted to it [28]. Prevalence rates of overweight and obesity are higher in urban peoples compared to rural peoples living in Bangladesh. Hoque et al., 2015 reported higher average annual rate of reduction of underweight was found among wealthier, highly educated, urban-living women, while a higher average annual rate of increase of overweight was found among poorer, uneducated, rural-living women [29]. Tanwi et al., 2019 reported prevalence of overweight and obesity was 34\% among urban Bangladeshi women [30], increased by 17.5\% between 1996 and 2011 [31]. Another study reveals that a nearly 30\% married women in Bangladesh are overweight [32]. Women's employment status was only associated with overweight or obesity for urban residents. Working urban women had a lower probability of being overweight. Socio-demographic factors including age, education, wealth index, marital status, watching TV and employment status were associated with the increased trend of overweight and obesity [33]. The highest prevalence of overweight and obesity were observed in those women with the highest education level and wealth, larger family size, living in urban areas and not being in paid employment [34].

\section{Lifestyle Issues}

According to the WHO-Diabetes country profile of Bangladesh in 2016, the physical inactivity was prevailing more than $25 \%$ of population. Bangladeshi women more at health risk than men due to inactivity. Two big reasons to diabetes among Bangladeshi people are carbohydrate-dependent food pattern and sedentary lifestyle [35-37]. While males can go outside, socialize and take part in outdoor activities such as cricket or football or cycling, females are often confined to domestic chores and not allowed to go outside freely. Parents are likely to restrict or discourage their daughters from outdoor activities such as recreational walking or bicycling. Young females are vulnerable to crime while travelling and so are more likely to avoid walking. Uddin et.al, 2019 reported that $80 \%$ young adults in Dhaka City, did not meet the WHO recommended level of physical activity (150 minutes of moderate- to vigorous-intensity activity per week) for optimal health, with higher rates of insufficient activity among females than males [38].

Unplanned urbanization in the capital is clear, where people have very limited scope for physical activities. Even in the rural areas people now take rickshaw/vans or other rides to go to marketplaces. Evidence shows that prevalence of physical inactivity $35 \%$ to $38 \%$ in Bangladeshi adults aged 25 years and older [39]. Adults engage in high levels of sedentary behavior during waking hours, said another study [40]. Prevalence of self-reported depression was respectively $47.7 \%$ in Bangladesh. Lower frequency of vigorous physical activity was significantly associated with higher rates of depression diagnosed [41]. People with depressive disorders have a $65 \%$ greater risk of developing diabetes than the general population, which is a double-trouble according to the WHO [42].

\section{Regular Health Checkup}

Despite the high levels of diabetes and intermediate hyperglycemia, awareness and control of the condition is low in rural Bangladesh. In Bangladesh, one in three people over the age of 35 are diabetic or pre-diabetic, only $12 \%$ of them have their condition under control [43]. Fottrell et al., 2019 reported only $25 \%$ of diabetics were aware of their status, women with diabetes were $37 \%$ less likely than men to know that they were diabetic and, even among known diabetics, $75 \%$ had suboptimal control of the condition [44]. It is mentioned earlier that 1 in 10 Bangladeshi urban adult (aged $\geq 18$ years) have hyperglycemia, with dyslipidemia prevalent over $70 \%$ male and females. Among those aged over 35, the Bangladesh Demographic and Health Survey (BDHS) reported that approximately $25 \%$ had abnormal fasting glucose [45]. The glycated hemoglobin (HbA1c) method does not require the candidate to fast for eight hours or take glucose and he or she can have the test done by the HbA1c method any time [46]. However, for individuals diagnosed with diabetes, screening is associated with a reduction in mortality and cardiovascular disease risk [47].

\section{Tobacco Smocking}

Tobacco kills more than seven million people a year worldwide and responsible for 1 in 5 deaths in Bangladesh, according to the WHO, kills more than 161,000 people on average every year [48]. A number of experimental and clinical studies suggest that smoking decreases insulin sensitivity, and indirectly role plays in elevated blood sugar and LDL, decreased HDL and postprandial lipid intolerance [49-57]. A 2018 survey by BRAC University shows several risk factors of diabetes includes smoking (almost 60\%), abdominal obesity (43.3\%), hypertension (14.3\%), depression (43\%) whereas the incidence of routine bodily exercise (only 1.3\%) and the habit of consuming seasonal fruits as well 
as vegetables $(8.6 \%)$ remain significantly low among the people of Bangladesh [58]. Bangladesh has been identified as a highachieving country for several tobacco control measures, including tobacco taxation, health warning labels and anti-tobacco massmedia campaigns. The high level of achievement for Bangladesh in cigarette taxation is, however, contradicted by an increase in per capita cigarette consumption [59]. Urban male smokers in Bangladesh consume more cigarettes than bidis and smoke more per day than rural smokers. More than half of Bangladeshi men over the age of 25 years smoke cigarettes or bidis, small handmade cigarettes containing about one fourth the amount of tobacco found in cigarettes [60]. Despite the reduction in overall tobacco use, the male smoking prevalence in Bangladesh is still high at 37\% [61]. Although, government is taking initiatives from administration, more than one fourth $(25.5 \%)$ of the police personnel in Bangladesh are currently smokers and this should be intervened [62].

\section{Other Issues}

(a) Climate and Environment: Not only food and lifestyle, global warming also plays an important role in diabetes prevalence. A Netherlands based study in CNN Health says, "a 1-degree Celsius rise in environmental temperature could account for more than 100,000 new diabetes cases per year in the USA alone" [18]. A similar study says Bangladesh will exceed 35-degree Celsius before the end of the century [63]. Consuming arsenic contaminated food grains could be another reason of high diabetes prevalence [64]. In sex-stratified analyses with 641 subjects from rural Bangladesh, Paul et al., 2019 reported arsenic exposure $(50.01-150 \mu \mathrm{g} / \mathrm{L})$ showed a clearer pattern of dosedependent risk for hyperglycemia in females than males [65]. Again, 15\% of expecting women are diagnosed with gestational diabetes among these $60 \%$ contribute to permanent diabetes within 10 years, says Dr Samsad Jahan (professor of Obstetrics and Gynecology, BIRDEM) [66].

(b) Skipping Meals: Breakfast skipping is highly prevalent among urban adult population with significant association of obesity in Bangladesh [67, 68]. Kabir et al., 2018 reported skipping breakfast by public university students for cost saving [69] and Bipasha et al., 2014 reported the same by private university students due to late sleep and rush for classes in the morning [28]. Either way, skipping breakfast hikes both obesity and diabetes risk [70].

(c) Fatty and Fried Food after Religious Fasting: It is common knowledge that fasting has myriad health benefits. Fasting during Ramadan is significantly associated with decrease in blood lipid profile, blood pressures, glucose, and HbA1C level among diabetic patients [71-76]. The total energy intake decreases during Ramadan, whereas the dietary fat consumption increases because of an augmentation of fatty food that does not occur during other periods [77]. Following Prophetic tradition, it is customary to open the fast with dates, which is unique in its nutrient content ( $\beta$-D-glucan, a soluble fiber) that gives the stomach a 'full' feeling [78].

(d) Food Adulteration: ICDDR, B, estimated 150 food items in the country. More than $50 \%$ of the food samples they tested were adulterated reported by the Institute of Public Health (IPH). Undoubtedly human health is now under the domination of formalin, in Bangladesh about 400 tons of formalin is being imported which are goes to human stomach, creates deadly mistreats on long term exposure [79]. Several studies highlighted formaldehyde-induced neuro-degeneration, diabetes risk and diabetes-associated cognitive impairments [80-83]. Even more unfortunate is the fact that nefarious practice of food adulteration increases exponentially during the month of Ramadan in Bangladesh, according to a study of European Journal of Sustainable Development Research, 2019 [84]. The number of patients suffering from cancer, diabetes, and kidney diseases is on the rise due to food adulteration [85-88].

(e) Child Marriage: According to UNICEF, Bangladesh has the fourth highest prevalence rate of child marriage in the world, and the second highest number of absolute child brides -4.5 million. Around $30 \%$ of girls in Bangladesh married before the age of 15 and nearly $80 \%$ gotmarried before the age of 18 [89-91]. The prevalence of nutritional deficiency was relatively higher among rural, illiterate and early married women and among those with a low standard of living [92]. Child marriage, low-birth-weight, mother nutrition and diabetes closely related to each other [46], [92-95].

(f) Low Health Literacy (LHL): In low-income countries such as Bangladesh, the less than optimum use of services could be due to LHL. Emphasis on health literacy has been inadequate. And also, health service delivery is pluralistic with a mix of public, private and informally trained healthcare providers [96]. Despite the high levels of diabetes and intermediate hyperglycemia, awareness and control of the condition is low [44]. In a cross sectional study in urban population of Bangladesh, more than $60 \%$ of the diabetic patients had inadequate functional health literacy of them andnearly $90 \%$ had inadequate glycemic control (HbA1c > 8\%). Therefore, Mehzabin et al., 2019 concluded that LHL is consistently associated with inadequate glycemic control [97]. LHL also indicates that the health promotion techniques are not used appropriately and it is linked to the declining health status of the people and results in low compliance to disease prevention programs. Also, Islam et al., 2018 concluded that diabetes-related health literacy in rural Bangladesh is a major factor associated with diabetic retinopathy (DR) screening [98]. Diabetes prevention and control efforts in this population must include large-scale awareness initiatives which focus not only on high-risk individuals but the whole population. Innovations in increasing diabetes knowledge and health behavior change are recommended specially for females, those with lower education and less income [99].

(g) Malnutrition \& Other Social Challenges: Mother nutrition and diabetes situation is already discussed.Very little is known about the occurrence of T1DM in resource-poor countries and particularly in their rural hinterlands. Bangladesh is among the 20 countries where $80 \%$ undernourished children are living. Underweight (weight-for-age $z$-score $<-2$ ) among children aged less than five years is more than $40 \%$ and nearly one-third of women are undernourished with body mass index of $<18.5 \mathrm{~kg} /$ $\mathrm{m}^{2}$ in Bangladesh [100]. The IDF atlas estimated the incidence of type 1 diabetes in Bangladesh as 4.2 new cases of T1DM/100,000 children (0-14 years)/year, in 2013 [20]. The social challenges faced by T1DM children are numerous. Many of them are poor, with little access to education. They are often considered a burden on the family, especially girls; they have little prospect of getting married or being employed. Diabetes is likely to be hidden from 
society, prospective spouse and employer, often with far-reaching consequences. Lack of motivation, inability to manage common complications e.g., hypoglycemia, sick day management, drop out from the clinic (which may be due to lack of motivation or extra cost involved in travel), psychological issues, are other common problems.

\section{Conclusion}

The prevalence of type 2 diabetes showed an increasing trend in both urban and rural population in Bangladesh. People with no education, lower socio-economic status, and those who lived in disadvantaged regions in terms of education and economic profile are found lacking of diagnosis, treatment, and control of diabetes. Emphasizing medication adherence with multiple comorbid diseases should be strongly considered in future diabetes management programs to improve glycemic control in patients with type 2 diabetes. Recently, Telenor Health and $\mathrm{DAB}$ have launched the first- ever diabetes management service, Dia360, to help people with diabetes manage their blood sugar levels and reduce risks of complications. People can enroll in three DAB centers in Dhaka-Bangladesh Institute of health and Sciences, BIRDEM General Hospital, and the National Health Network Hospital. It has more than 400,000 diabetics registered at its tertiary center, BIRDEM in Dhaka.However, the most important thing is patient education, that the modern world is giving the highest priorities. Rich or poor, privileged or unprivileged, all segment of population should be brought under the arena of compliance through patient education, at least by health campaign. Both government, profit taking NGOs and pharmaceutical companies should take initiatives in this regard.

\section{Acknowledgment}

I'm thankful to Dr. Afsana Afroz, Department of Epidemiology and Preventive Medicine, School of Public Health and Preventive Medicine, Monash University, Melbourne, Australia for her valuable time to audit my paper and for her thoughtful suggestions. I'm also grateful to seminar library of Faculty of Pharmacy, University of Dhaka and BANSDOC Library, Bangladesh for providing me books, journal and newsletters.

\section{References}

[1]. Ali N, Akram R, Sheikh N, Sarker AR, Sultana M. Sex-specific prevalence, inequality and associated predictors of hypertension, diabetes, and comorbidity among Bangladeshi adults: results from a nationwide cross-sectional demographic and health survey. BMJ open. 2019 Sep 17; 9(9): e029364. PMID: 31530600. doi:10.1136/bmjopen-2019-029364

[2]. Mohiuddin AK. Diabetes Fact: Bangladesh Perspective. International Journal of Diabetes Research. 2019 Feb 24;2(1):14-20. doi: 10.17554/j. issn.2414-2409.2019.02.12.

[3]. Afroz A, Alam K, Ali L, Karim A, Alramadan MJ, Habib SH, et al. Type 2 diabetes mellitus in Bangladesh: a prevalence based cost-of-illness study. BMC health services research. 2019 Dec 1; 19(1): 601. doi:10.1186/ s12913-019-4440-3.

[4]. Islam JY, Zaman MM, Bhuiyan MR, Haq SA, Ahmed S, Al-Qadir AZ. Prevalence and determinants of hyperglycaemia among adults in Bangladesh: results from a population-based national survey. BMJ open. $2019 \mathrm{Jul}$ 1; 9(7):e029674. doi:10.1136/bmjopen-2019-029674.

[5]. Salahuddin T. The rising threat of NCDs in Bangladesh. The Daily Star. 2019 January 06.

[6]. Salahuddin T. Obesity is increasing among the younger generation in Bangladesh. The Daily Star. 2018 September 23.

[7]. Star Online Report 80 lakh Bangladeshis suffering from diabetes: State min- ister The Daily Star April 06, 2016.

[8]. Islam FM, Chakrabarti R, Islam MT, Wahab M, Lamoureux E, Finger RP et al. Prediabetes, diagnosed and undiagnosed diabetes, their risk factors and association with knowledge of diabetes in rural Bangladesh: The Bangladesh Population-based Diabetes and Eye Study. J Diabetes. 2016 Mar; 8(2):2608. PMID: 25851830.doi: 10.1111/1753-0407.12294.

[9]. Fottrell E, Ahmed N, Morrison J, Kuddus A, Shaha SK, King C, Jennings $\mathrm{H}$, Akter K, Nahar T, Haghparast-Bidgoli H, Khan AA. Community groups or mobile phone messaging to prevent and control type 2 diabetes and intermediate hyperglycaemia in Bangladesh (DMagic): a cluster-randomised controlled trial. The Lancet Diabetes \& Endocrinology. $2019 \mathrm{Mar}$ 1;7(3):200-12. doi:10.1016/S2213-8587(19)30001-4.

[10]. Shariful Islam SM, Lechner A, Ferrari U, Laxy M, Seissler J, Brown J, et al. Healthcare use and expenditure for diabetes in Bangladesh. BMJ global health. 2017 Jan 3; 2(1):e000033. PMID: 28588991.doi:10.1136/bmjgh-2016-000033

[11]. Das H, Banik S. Prevalence of dyslipidemia among the diabetic patients in southern Bangladesh: A cross-sectional study. Diabetes Metab Syndr. 2019 Jan - Feb;13(1):252-257. PMID: 30641707.doi: 10.1016/j. dsx.2018.09.006.

[12]. Mohammad QD, Habib M, Mondal BA, Chowdhury RN, Hasan MH, Hoque MA, et al. Stroke in Bangladeshi patients and risk factor. Mymensingh Med J. 2014 Jul; 23(3):520-9.

[13]. Afroz A, Zhang W, Wei Loh AJ, Jie Lee DX, Billah B. Macro- and microvascular complications and their determinants among people with type 2 diabetes in Bangladesh. Diabetes Metab Syndr. 2019 Sep - Oct; 13(5):29392946. doi: 10.1016/j.dsx.2019.07.046.

[14]. National Institute of Health (UK). Stay on TRACK To Prevent Blindness From Diabetes. Available From: https://www.nei.nih.gov/sites/default/files/ nehep-pdfs/NDM_SM_Toolkit_2015.pdf

[15]. American Association of Diabetes Educators. Resources for People Living with Diabetes (Monitoring). Available From: https://www.diabeteseducator.org/living-with-diabetes/aade7-self-care-behaviors/aade7-self-care-behaviors-monitoring

[16]. Mohiuddin AK. Domination of Nephrotic Problems among Diabetic Patients of Bangladesh. Archives of Nephrology and Urology. 2018; 009-016. DOI: 10.26502/anu.2644-2833002

[17]. Vanderlee L, Ahmed S, Ferdous F, Farzana FD, Das SK, Ahmed T, et al. Self-care practices and barriers to compliance among patients with diabetes in a community in rural Bangladesh. Int J Diabetes Dev Ctries. 2016; 36: 320. DOI: $10.1007 / \mathrm{s} 13410-015-0460-7$

[18]. Azad A. How climate change will affect your health. CNN health. 2018 October 12.

[19]. Diabetic Association of Bangladesh. WDF-494 Extension of Diabetic Retinopathy Care in Bangladesh. Available from: https://www.dab-bd.org/ sub-page.php?sub_category=35

[20]. Azad, Kishwar. "Type 1 diabetes: The Bangladesh perspective." Indian journal of endocrinology and metabolism. 2015; 19(1): S9-S11. doi: 10.4103/2230-8210.155344.

[21]. Alam MM, Hawlader MDH, Wahab A, Hossain MD, Nishat SA, Zaman $S$, et al. Determinants of overweight and obesity among urban schoolgoing children and adolescents: a case-control study in Bangladesh. Int J Adolesc Med Health. 2019 May 9. PMID: 31075080. doi: 10.1515/ ijamh-2018-0034.

[22]. Al Muktadir MH, Islam MA, Amin MN, Ghosh S, Siddiqui SA, Debnath D, et al. Nutrition transition - Pattern IV: Leads Bangladeshi youth to the increasing prevalence of overweight and obesity. Diabetes Metab Syndr. 2019 May - Jun;13(3):1943-1947. doi: 10.1016/j.dsx.2019.04.034.

[23]. Goon S, Bipasha MS, Islam S. Fast food consumption and obesity risk among university students of Bangladesh. Eur J Prev Med 2014; 2:99e104.

[24]. World Diabetes Day 2018. "Access to insulin is a human right" In conversation with Professor AK Azad Khan, President, Diabetic Association of Bangladesh. The Daily Star, 2018 November 14.

[25]. Hasib NI. Children getting type 2 diabetes 'alarmingly' in Bangladesh. bdnews24.com, 2016 April 06.

[26]. Hossain MS, Siddiqee MH, Ferdous S, Faruki M, Jahan R, Shahik SM, et al. Is Childhood Overweight/Obesity Perceived as a Health Problem by Mothers of Preschool Aged Children in Bangladesh? A Community Level Cross-Sectional Study. Int J Environ Res Public Health. 2019 Jan 12; 16(2). doi: 10.3390/ijerph16020202.

[27]. Chaity AJ. Obesity blamed for alarming rise in childhood diabetes. DhakaTribune. 2017 November 13.

[28]. Bipasha M, Goon S. Fast food preferences and food habits among students of private universities in Bangladesh. South East Asia Journal of Public Health. 2014; 3(1): 61-64. DOI: 10.3329/seajph.v3i1.17713

[29]. Hoque ME, Long KZ, Niessen LW, Al Mamun A. Rapid shift toward overweight from double burden of underweight and overweight among Bangla- 
deshi women: a systematic review and pooled analysis. Nutr Rev. 2015 Jul; 73(7):438-47. doi: 10.1093/nutrit/nuv003.

[30]. Tanwi TS, Chakrabarty S, Hasanuzzaman S, Saltmarsh S, Winn S. Socioeconomic correlates of overweight and obesity among ever-married urban women in Bangladesh. BMC public health. 2019 Dec; 19(1):842. doi:10.1186/s12889-019-7221-3

[31]. Banik S, Rahman M. Prevalence of Overweight and Obesity in Bangladesh: a Systematic Review of the Literature. Curr Obes Rep. 2018 Dec; 7(4):247253. doi: 10.1007/s13679-018-0323-x.

[32]. Biswas T, Garnett SP, Pervin S, Rawal LB. The prevalence of underweight, overweight and obesity in Bangladeshi adults: Data from a national survey. PloS one. 2017 May 16;12(5): e0177395. doi:10.1371/journal. pone. 0177395

[33]. Chowdhury Muhammad Abdul Baker, Adnan MM, Hassan MZ. Trends, prevalence and risk factors of overweight and obesity among women of reproductive age in Bangladesh: a pooled analysis of five national cross-sectional surveys. BMJ open. 2018 Jul 19; 8(7):e018468. PMID: 30030307. doi:10.1136/bmjopen-2017-018468.

[34]. Biswas T, Uddin MJ, Mamun AA, Pervin S, P Garnett S. Increasing prevalence of overweight and obesity in Bangladeshi women of reproductive age: Findings from 2004 to 2014. PLoS One. 2017 Jul 28; 12(7):e0181080. PMID: 28753680. doi: 10.1371/journal.pone.0181080.

[35]. Guthold R, Stevens GA, Riley LM, Bull FC. Worldwide trends in insufficient physical activity from 2001 to 2016: a pooled analysis of 358 population-based surveys with $1 \bullet 9$ million participants. Lancet Glob Health. 2018 Oct; 6(10): e1077-e1086. DOI: 10.1016/S2214-109X(18)30357-7.

[36]. Mahbub I. Why Is Diabetes on The Rise in Bangladesh? Web Future Startup, 2016 October 25. Available From: https://futurestartup.com/2016/10/25/ why-is-diabetes-on-the-rise-in-bangladesh/.

[37]. Tareq S. Obesity is increasing among the younger generation in Bangladesh. The Daily Star, 2018 September 23.

[38]. Uddin Riaz, Asaduzzaman Khan, Nicola W Burton. Prevalence and sociodemographic patterns of physical activity among Bangladeshi young adults. Journal of health, population, and nutrition. 2017 Jul 14; 36: 31. doi:10.1186/s41043-017-0108-y

[39]. Moniruzzaman Mohammad, Ahmed MS, Zaman MM. Physical activity levels and associated socio-demographic factors in Bangladeshi adults: a cross-sectional study. BMC public health. 2017 Jan 11; 17(1):59. PMID: 28077119. doi:10.1186/s12889-016-4003-z.

[40]. Vancampfort D, Firth J, Schuch F, Rosenbaum S, De Hert M, Mugisha J, et al. Physical activity and sedentary behavior in people with bipolar disorder: A systematic review and meta-analysis. J Affect Disord. 2016 Sep 1; 201:145-52. doi: 10.1016/j.jad.2016.05.020.

[41]. Bishwajit Ghose, O'Leary DP, Ghosh S, Yaya S, Shangfeng T, Feng Z. Physical inactivity and self-reported depression among middle- and older-aged population in South Asia: World health survey. BMC geriatrics. $2017 \mathrm{Apr}$ 28; 17(1):100. PMID: 28454520.doi:10.1186/s12877-017-0489-1.

[42]. WHO Bangladesh. Double trouble: diabetes and depression. Available from: http://www.searo.who.int/bangladesh/depressiondoubletrouble/en/

[43]. Aowsaf SMA. Diabetes management service launched in Bangladesh. DhakaTribune. 2018 September 25

[44]. Fottrell E, Ahmed N, Shaha SK, Jennings H, Kuddus A, Morrison J, Akter K, Nahar B, Nahar T, Haghparast-Bidgoli H, Khan AA. Diabetes knowledge and care practices among adults in rural Bangladesh: a cross-sectional survey. BMJ global health. 2018 Jul 1;3(4):e000891. doi:10.1136/bmjgh-2018-000891

[45]. Fottrell E, Ahmed N, Shaha SK, Jennings H, Kuddus A, Morrison J, et al. Distribution of diabetes, hypertension and non-communicable disease risk factors among adults in rural Bangladesh: a cross-sectional survey. BMJ global health. 2018 Nov 1; 3(6):e000787., doi:10.1136/bmjgh-2018-000787

[46]. Palma P. A worrying picture of diabetes in Bangladesh. The Daily Star. 2018 November 14

[47]. Health Tips. Screening reduces mortality for detectable type 2 diabetics. The Daily Star. 2017 August 27.

[48]. Hasan MK. WHO: Tobacco responsible for 1 in 5 deaths in Bangladesh. DhakaTribune. 2018 June 01.

[49]. Bergman Bryan C, Leigh Perreault, Devon Hunerdosse, Anna Kerege, Mary Playdon, Ali M. Samek, et al. Novel and reversible mechanisms of smokinginduced insulin resistance in humans. Diabetes. 2012 Dec; 61(12): 31563166. PMID: 22966072. doi:10.2337/db12-0418

[50]. Kong C, Nimmo L, Elatrozy T, Anyaoku V, Hughes C, Robinson S, et al. Smoking is associated with increased hepatic lipase activity, insulin resistance, dyslipidaemia and early atherosclerosis in Type 2 diabetes. Atherosclerosis. 2001 Jun; 156(2):373-8.

[51]. Schofield Jonathan D, Yifen Liu, Prasanna Rao-Balakrishna, Rayaz A. Malik, Handrean Soran. Diabetes Dyslipidemia. Diabetes ther. 2016 Jun; 7(2): 203-219. PMID: 27056202. doi:10.1007/s13300-016-0167-x
[52]. Facchini FS, Hollenbeck CB, Jeppesen J, Chen YD, Reaven GM. Insulin resistance and cigarette smoking. Lancet. 1992 May 9; 339(8802):1128-30.

[53]. Bajaj Mandeep. Nicotine and insulin resistance: when the smoke clears. Diabetes. 2012 Dec; 61(12): 3078-3080. PMID: 23172960. doi:10.2337/ db12-1100

[54]. Kindred K. Harris, Mohan Zopey, Theodore C. Friedman. Metabolic effects of smoking cessation. Nature reviews Endocrinology. 2016 May; 12(5): 299-308. PMID: 26939981. doi:10.1038/nrendo.2016.32

[55]. Calcaterra V, Winickoff JP, Klersy C, Schiano LM, Bazzano R, Montalbano $\mathrm{C}$, et al. Smoke exposure and cardio-metabolic profile in youth with type 1 diabetes. Diabetol Metab Syndr. 2018 Jul 6;10:53. PMID: 29989097. doi: 10.1186/s13098-018-0355-0.

[56]. Rao Ch, Srinivasa, Emmanuel Subash Y. The effect of chronic tobacco smoking and chewing on the lipid profile. Journal of clinical and diagnostic research. 2013 Jan;7(1):31-4. PMID: 23449989. doi:10.7860/ JCDR/2012/5086.2663

[57]. Gossett LK, Johnson HM, Piper ME, Fiore MC, Baker TB, Stein JH. Smoking intensity and lipoprotein abnormalities in active smokers. Journal of clinical lipidology 2009 Dec; 3(6):372-8. PMID: 20161531. doi:10.1016/j. jacl.2009.10.008

[58]. Wasifuzzaman C. A review of prevalence, complications, risk factors, knowledge assessment, self-management, consciousness and treatment of diabetes mellitus in Bangladesh. Available From: http://dspace.bracu.ac.bd/xmlui/ handle/10361/10674

[59]. Nigar Nargis, AKM Ghulam Hussain, Mark Goodchild, Anne CK Quah, Geoffrey T Fong. A decade of cigarette taxation in Bangladesh: lessons learnt for tobacco control. Bulletin of the World Health Organization. 2019 Mar 1; 97(3): 221-229. PMID: 30992635. doi:10.2471/BLT.18.216135

[60]. Dewan S Alam, Prabhat Jha, Chinthanie Ramasundarahettige, Peter Kim Streatfield, Louis W Niessen, Muhammad Ashique H Chowdhury, et al. Smoking-attributable mortality in Bangladesh: proportional mortality study. Bulletin of the World Health Organization. 2013 Oct 1; 91(10): 757-764. PMID: 24115799. doi:10.2471/BLT.13.120196

[61]. Nargis N, Thompson ME, Fong GT, Driezen P, Hussain AK, Ruthbah UH, et al. Prevalence and Patterns of Tobacco Use in Bangladesh from 2009 to 2012: Evidence from International Tobacco Control (ITC) Study. PloS one. 2015 Nov 11; 10(11): e0141135. PMID: 26559051. doi:10.1371/journal. pone. 0141135

[62]. Khan MK, Hoque HE, Ferdous J. Knowledge and Attitude Regarding National Tobacco Control Law and Practice of Tobacco Smoking among Bangladesh Police. Mymensingh Med J. 2019 Oct; 28(4):752-761.

[63]. Tribune Desk. Temperature in Bangladesh to rise to deadly heights by end of century. DhakaTribune. 2017 August 03.

[64]. Mohiuddin AK. Domination of Pollutant Residues Among Food Products of South-East Asian Countries. Acta Scientific Pharmaceutical Sciences. 2019; 3:75-9.

[65]. Paul SK, Islam MS, Hasibuzzaman MM, Hossain F, Anjum A, Saud ZA, et al. Higher risk of hyperglycemia with greater susceptibility in females in chronic arsenic-exposed individuals in Bangladesh. Sci Total Environ. 2019 Jun 10; 668:1004-1012. doi: 10.1016/j.scitotenv.2019.03.029.

[66]. Chaity AJ. 15\% pregnant women diagnosed with diabetes. DhakaTribune. 2017 November 14

[67]. Goon S, Islam MS. Breakfast skipping and obesity risk among urban adults in Bangladesh.Int J Public Health Sci. 2014; 3:15-22.

[68]. Khan A, Khan SR, Burton NW. Missing breakfast is associated with overweight and obesity in Bangladeshi adolescents. Acta Paediatr. 2019 Jan; 108(1):178-179. doi: 10.1111/apa.14553.

[69]. Kabir A, Miah S, Islam A. Factors influencing eating behavior and dietary intake among resident students in a public university in Bangladesh: A qualitative study. PLoS One. 2018 Jun 19; 13(6):e0198801. doi: 10.1371/ journal.pone.0198801.

[70]. Mohiuddin AK. Skipping Breakfast Everyday Keeps Well-Being Away. Acta Medica. 2019 Mar; 50(1): 26-33. doi:10.32552/2019.ActaMedica.331.

[71]. Bener A, Yousafzai MT. Effect of Ramadan fasting on diabetes mellitus: a population-based study in Qatar. J Egypt Public Health Assoc. 2014 Aug; 89(2):47-52. doi: 10.1097/01.EPX.0000451852.92252.9b.

[72]. Yeoh EC, Zainudin SB, Loh WN, Chua CL, Fun S, Subramaniam T, et al. Fasting during Ramadan and Associated Changes in Glycaemia, Caloric Intake and Body Composition with Gender Differences in Singapore. Ann Acad Med Singapore. 2015 Jun; 44(6):202-6.

[73]. Bener A, A Al-Hamaq AOA, Öztürk M, Çatan F, Haris PI, Rajput KU, Ömer A. Effect of ramadan fasting on glycemic control and other essential variables in diabetic patients. Ann Afr Med. 2018 Oct-Dec;17(4):196-202. doi: 10.4103/aam.aam_63_17.

[74]. Ahmed MH, Husain NE, Elmadhoun WM, Noor SK, Khalil AA, Almobarak AO. Diabetes and Ramadan: A concise and practical update. Journal of family medicine and primary care. 2017 Jan-Mar; 6(1):11-18. PMID: 
29026740. doi:10.4103/2249-4863.214964

[75]. Malinowski B, Zalewska K, Wesierska A, Sokołowska MM, Socha M, Liczner $\mathrm{G}$, et al. Intermittent Fasting in Cardiovascular Disorders-An Overview. Nutrients. 2019 Mar; 11(3): 673. PMID: 30897855. doi:10.3390/ nu1 1030673

[76]. Siaw MY, Chew DE, Toh MP, Seah DE, Chua R, Tan J, et al. Metabolic parameters in type 2 diabetic patients with varying degrees of glycemic control during Ramadan: An observational study. Journal of diabetes investigation. 2016 Jan; 7(1):70-5. PMID: 26816603. doi:10.1111/jdi.12374

[77]. Khaled Boumédiène Méghit, Slimane Belbraouet. Effect of Ramadan fasting on anthropometric parameters and food consumption in 276 type 2 diabetic obese women. International journal of diabetes in developing countries. 2009 Apr-Jun; 29(2): 62-68. PMID: 20142870 doi:10.4103/09733930.53122

[78]. Ali SA, Parveen N, Ali AS. Links between the Prophet Muhammad (PBUH) recommended foods and disease management: A review in the light of modern superfoods. International journal of health sciences 2018 Mar-Apr; 12(2): 61-69. PMID: 29599697.

[79]. Mohiuddin AK. The Mysterious Domination of Food/Drinking Water Contaminants and Adulterants in Bangladesh. PharmaTutor. 2019 Jan 1;7(1):42-58. doi:10.29161/PT.v7.i1.2019.42.

[80]. Tan T, Zhang Y, Luo W, Lv J, Han C, Hamlin JNR, et al. Formaldehyde induces diabetes-associated cognitive impairments. FASEB J. 2018 Jul; 32(7): 3669-3679. doi: 10.1096/f. 201701239R.

[81]. Hipkiss Alan R. Depression, Diabetes and Dementia: Formaldehyde May Be a Common Causal Agent; Could Carnosine, a Pluripotent Peptide, Be Protective?. Aging and disease. 2017 Apr; 8(2): 128-130. PMID: 28400979. doi:10.14336/AD.2017.0120.

[82]. Tulpule K, Dringen R. Formaldehyde in brain: an overlooked player in neurodegeneration?. J Neurochem. 2013 Oct; 127(1): 7-21. doi: 10.1111/ jnc. 12356.

[83]. Grotton C. Research Update: Protect Against Formaldehyde Exposure. Life Extension Magazine ${ }^{\oplus}$, Issue: Jan 2019.

[84]. Mohiuddin AK. Chemical Contaminants and Pollutants in the Measurable Life of Dhaka City. European Journal of Sustainable Development Research. 2019; 3(2): em0083. https://doi.org/10.29333/ejosdr/5727

[85]. Ullah A. Sale of Adulterated Spice Powder: Public health at risk. The Daily Sun. 2019 October 16.

[86]. Staff Correspondent. Food adulteration rings alarm bell: STAR-RDRS roundtable told most food items adulterated, pose lethal risks to public health. The Daily Star. 2011 August 11.

[87]. Majed N, Real MIH, Akter Mand Azam HM. Food Adulteration and BioMagnification of Environmental Contaminants: A Comprehensive Risk Framework for Bangladesh. Front.Environ.Sci. 2016; 4:34. doi: 10.3389/ fenvs.2016.00034
[88]. Chowdhury MFI. Evaluating Position of Bangladesh to Combat 'Adulterated Food' Crisis in Light of Human Rights. OSR Journal Of Humanities And Social Science (IOSR-JHSS). 2014 Mar; 19(3): 45-54.

[89]. Child Marriage in Bangladesh. Marry Before Your House is Swept Away. Human Rights Watch, 2015 June 9.

[90]. Kamal SM, Hassan CH, Alam GM, Ying Y. Child marriage in Bangladesh: trends and determinants. J Biosoc Sci. 2015 Jan; 47(1):120-39. doi: $10.1017 /$ S0021932013000746.

[91]. Hossain MG, Mahumud RA, Saw A. PREVALENCE OF CHILD MARRIAGE AMONG BANGLADESHI WOMEN AND TREND OF CHANGE OVER TIME. J Biosoc Sci. 2016 Aug; 48(4): 530-8. doi $10.1017 /$ S0021932015000279.

[92]. Zahangir MS, Hasan MM, Richardson A, Tabassum S. Malnutrition and non-communicable diseases among Bangladeshi women: an urbanrural comparison. Nutrition \& diabetes. 2017 Mar 20;7(3):e250. PMID: 28319102. doi:10.1038/nutd.2017.2

[93]. Silva-Zolezzi I, Samuel TM, Spieldenner J. Maternal nutrition: opportunities in the prevention of gestational diabetes. Nutrition reviews 2017 Jan; 75(suppl 1):32-50. PMID: 28049748. doi:10.1093/nutrit/nuw033

[94]. Tunçer M. Fetal malnutrition in infants born to diabetic mothers. Turk J Pediatr. 1982 Oct-Dec; 24(4):245-9.

[95]. Independent Online Desk. Malnutrition major cause of premature child birth in Bangladesh. The Independent. 2018 March 23.

[96]. Das S, Mia MN, Hanifi SM, Hoque S, Bhuiya A. Health literacy in a community with low levels of education: findings from Chakaria, a rural area of Bangladesh. BMC Public Health. 2017 Feb 16;17(1):203. doi: 10.1186/ s12889-017-4097-y.

[97]. Mehzabin R, Hossain KJ, Moniruzzaman M, Sayeed SJ. Association of Functional Health Literacy with Glycemic Control: A Cross Sectional Study in Urban Population of Bangladesh. Journal of Medicine. 2019 Jan 1;20(1):19-24. doi:10.3329/jom.v20i1.38816.

[98]. Islam FMA, Kawasaki R, Finger RP. Factors associated with participation in a diabetic retinopathy screening program in a rural district in Bangladesh. Diabetes Res Clin Pract. 2018 Oct; 144:111-117. doi: 10.1016/j. diabres.2018.08.012.

[99]. Siddique MK, Islam SM, Banik PC, Rawal LB. Diabetes knowledge and utilization of healthcare services among patients with type 2 diabetes mellitus in Dhaka, Bangladesh. BMC health services research. 2017 Aug 22;17(1):586. PMID: 28830414. doi:10.1186/s12913-017-2542-3.

[100]. Ahmed T, Mahfuz M, Ireen S, Ahmed AS, Rahman S, Islam MM, et al. Nutrition of children and women in Bangladesh: trends and directions for the future. Journal of health, population, and nutrition. 2012 Mar; 30(1): 1-11. doi:10.3329/jhpn.v30i1.11268 